\title{
ANÁLISE DA EVOLUÇÃO DAADESÃO DE EMPRESAS AO ÍNDICE DE SUSTENTABILIDADE EMPRESARIAL (ISE)
}

\author{
Data de submissão: 28/03/2018 \\ Aceite: $17 / 07 / 2018$ \\ Vicente Lima Crisóstomo ${ }^{1}$ \\ Celia Maria Braga Carneiro ${ }^{2}$ \\ Lorena Albuquerque da Silva Gomes ${ }^{3}$
}

\section{RESUMO}

Sob o marco teórico da Teoria da Divulgação Voluntária e do enfoque Stakeholder, este trabalho tem como objetivo analisar a evolução da adesão e a permanência das empresas no Índice de Sustentabilidade Empresarial (ISE) da B3 (Brasil, Bolsa, Balcão). Baseado em análise de conteúdo do questionário ISE aplicado às empresas candidatas e fazendo-se uma análise descritiva do número de empresas presentes no ISE no período de 2005 a 2015, juntamente com testes de diferença de proporções, pode-se observar um crescente interesse das empresas brasileiras em estarem listadas no ISE. A análise foi feita com base em todas as 72 empresas que já estiveram presentes no ISE observando-se o crescimento do número de empresas que lá estão a cada ano. Os resultados indicam a superior proporção de empresas que permanecem no ISE em anos consecutivos. De modo similar, também é significativa a proporção de empresas que optam por permitir a divulgação do conteúdo de seu questionário de candidatura caso sejam aprovadas no processo. Adicionalmente, é importante destacar as dimensões do questionário ISE que indagam sobre aspectos relativos a várias ações da empresa além da típica Responsabilidade Social Corporativa (dimensão social), envolvendo também, fortemente, as dimensões Governança Corporativa e Econômica.

Palavras-chave: Responsabilidade Social Corporativa; Sustentabilidade; Índice de Sustentabilidade Empresarial; Adesão; Divulgação de questionários.

\footnotetext{
1 Professor da Universidade Federal do Ceará (UFC). Doutor em Finanças pela Universidade de Valladolid/Espanha. Mestre em Ciências da Computação pela Universidade Federal de Santa Catarina (UFSC). Graduado em Computação e em Ciências Contábeis pela Universidade Federal do Ceará (UFC). E-mail:vlc@ufc.br.

2 Professora da Universidade Federal do Ceará (UFC). Doutora em Gestão de Empresas pela Universidade de Coimbra/Portugal. Mestre em Controladoria e Contabilidade pela Universidade de São Paulo (USP). Graduada em Ciências Contábeis pela Universidade Federal do Ceará.

E-mail: celiabragac@hotmail.com.

3 Bolsista de Iniciação Científica CNPq, graduanda em Secretariado Executivo pela Universidade Federal do Ceará (UFC).

E-mail: lores.gomes@hotmail.com
} 


\section{INTRODUÇÃO}

As empresas têm passado a ser avaliadas não somente por seu desempenho financeiro, mas também por indicadores não financeiros e pela forma como se relacionam com uma ampla gama de stakeholders, além dos tradicionais - acionista, gestor e credor - articulados pela Teoria da Agência (JENSEN; MECKLING, 1976) e Teoria dos Stakeholders (FREEMAN; PHILLIPS, 2002; FREEMAN; WICKS; PARMAR, 2004; MCVEA; FREEMAN, 2005). Pesquisas em estratégia têm proposto que há um conjunto de novas pressões sobre as empresas, relativas às suas ações no contexto da comunidade/sociedade e não só como criadoras de riqueza para seus acionistas. Esta realidade tem levado empresas a integrarem preocupações sociais e com sustentabilidade a seu planejamento estratégico, a partir da implantação do conceito filosófico de desenvolvimento sustentável, promovendo a sustentabilidade por motivações associadas à legitimação de suas ações, reputação e visibilidade (FREEMAN; WICKS; PARMAR, 2004; GALAN, 2006; COCHRAN, 2007; FARIA; SAUERBRONN, 2008; EUGÉNIO, 2010; TILLING; TILT, 2010; REAST et al., 2013; CRISÓSTOMO; FREIRE, 2015).

A Responsabilidade Social e a Sustentabilidade têm sido pesquisadas sob distintos enfoques. Destacam-se a questão conceitual, a importância, a evolução e as motivações das organizações para empreenderem tais ações (COCHRAN, 2007; DAHLSRUD, 2008; WILLIAMS; AGUILERA, 2008). A busca por fatores determinantes da Responsabilidade Social e a Sustentabilidade tem encontrado evidência associada a fatores institucionais como também a atributos das organizações, notadamente o desempenho de empresas, em diferentes mercados (MARGOLIS; WALSH, 2001; BAUGHN; BODIE; MCINTOSH, 2007; DOH et al., 2010; CRISÓSTOMO; FREIRE; VASCONCELLOS, 2011).

A pesquisa sobre o grau de atividade de Responsabilidade Social e Sustentabilidade das empresas tem adotado uma grande diversidade de métricas que possibilitem avaliar o desempenho social das organizações em setores diversos e em distintos mercados (ORLITZKY; SCHMIDT; RYNES, 2003). Neste contexto, parece relevante a questão da divulgação de informações, que tem sido apontada pela literatura como relevante por questões de transparência e como forma de viabilizar a avaliação externa (ADAMS, 2008; NASCIMENTO et al., 2009; BOUTEN et al., 2011).

A divulgação facultativa destas informações aliada à flexibilidade de formatos utilizados para sua divulgação tem contribuído para a existência de distintas métricas. Neste contexto surge a atuação de entidades externas especializadas em disclosure e em métricas de avaliação como a Global Reporting Initiative (GRI) e entidades do mercado. Tais entidades coletam dados de empresas e desenvolvem indicadores de Responsabilidade Social e Sustentabilidade[1]. Nesta mesma linha de atuação pode-se considerar os fundos de investimentos que investem em empresas socialmente responsáveis como também os índices de mercado que avaliam empresas sob os aspectos da Responsabilidade Social e Sustentabilidade (ORSATO et al., 2015). Estas entidades têm servido também como instituições intermediárias de avaliação para o mercado (STATMAN, 2006; DOH; HOWTON; HOWTON , SIEGEL, 2010). No século XXI surgiram índices de mercado com carteiras compostas por empresas que apresentam mais elevados padrões de Responsabilidade Social e Sustentabilidade de acordo com critérios devidamente publicados. Este é o caso do Dow Jones Sustainability Index (DJSI), da Bolsa de New York, cuja carteira congrega as empresas consideradas como com maior capacidade de criar valor para os acionistas no longo prazo, levando-se em conta os aspectos econômicos, ambientais e sociais (MYNHARDT; MAKARENKO; PLASTUN, 2017). No Brasil, o Índice de Sustentabilidade Empresarial (ISE), da B3 (Brasil, Bolsa, Balcão), tem-se apresentado como um índice relevante, destacadamente para as empresas que investem e divulgam suas ações de Responsabilidade Social e Sustentabilidade, haja vista a promoção positiva que se tem feito do ISE e o crescente número de empresas que tem pleiteado fazer parte da carteira ISE a cada ano (BM\&FBOVESPA, 2016). 
A importância que índices de Responsabilidade Social e Sustentabilidade têm ganhado suscita a seguinte questão de pesquisa: Há interesse das empresas em divulgarem seu grau de preocupação com Responsabilidade Social e Sustentabilidade por meio de índices de mercado? Este trabalho tem como objetivo analisar, a partir da avaliação da adesão ao Índice de Sustentabilidade Empresarial (ISE) e da persistência da presença das empresas no referido índice, como também da divulgação voluntária das respostas aos questionários, o interesse das empresas em divulgar sua estratégia e ações relativas à Responsabilidade Social e Sustentabilidade por meio da presença no ISE.

Para uma amostra composta por todas as 72 empresas que já figuraram no ISE, pelo menos em um ano, no período 2005-2015, os resultados indicam um crescente interesse das empresas em participar do índice e em permanecer no mesmo. Há também uma tendência crescente de divulgação dos conteúdos dos questionários respondidos pelas empresas.

O artigo está estruturado em 5 seções além desta introdução. Na seção 2 apresenta-se uma contextualização acerca da Responsabilidade Social Corporativa e Sustentabilidade e o Índice de Sustentabilidade Empresarial (ISE). A seção 3 apresenta a metodologia utilizada. A seção 4 relata a análise dos resultados da pesquisa e na seção 5 são apresentadas as considerações finais.

\section{RESPONSABILIDADE SOCIAL CORPORATIVA E SUS- TENTABILIDADE}

\subsection{Aspectos conceituais}

O livro Social Responsibilities of the Businessman de Howard R. Bowen, de 1953, foi pioneiro na abordagem do tema sobre responsabilidade social no âmbito empresarial (CARROLL, 1999). Em décadas mais recentes, a partir de transformações no meio ambiente e na sociedade, conceitos como Responsabilidade Social Empresarial (RSE)/Corporativa (RSC), Governança Corporativa, Gestão Ambiental, Sustentabilidade e Desenvolvimento Sustentável foram sendo incorporados ao cenário organizacional, talvez por pressões sociais e também por avanços no contexto legal e institucional (WOOD, 1991; COCHRAN, 2007). Apesar de divergências conceituais, parece haver uma interseção relativa à atitude de responsabilidade e consciência organizacional perante os stakeholders e o meio ambiente (COCHRAN, 2007; DAHLSRUD, 2008; MILANI et al., 2012).

A pesquisa tem avançado em distintas abordagens conceituais sobre a RSC, havendo um elenco de dimensões consideradas como componentes da Responsabilidade Social Corporativa (DAHLSRUD, 2008): meio ambiente, social, econômica e dimensão stakeholder. Estas dimensões fazem da RSC algo mais que somente a filantropia corporativa. Enquanto a filantropia está voltada para ações sociais que têm como alvo o público externo à entidade, a RSC engloba preocupações com os três tradicionais stakeholders articulados sob a Teoria da Agência - acionista, gestor, credor - (JENSEN; MECKLING, 1976) e mais um elenco de stakeholders que também interagem com a empresa como proposto pelo enfoque Stakeholder (FREEMAN; PHILLIPS, 2002; FREEMAN et al., 2012), como, por exemplo, os colaboradores, fornecedores, clientes, comunidade, governo, assim como o meio ambiente.

Propostas conceituais para a RSC aludem à conduta ética da empresa e à preocupação da mesma com o desenvolvimento sustentável que se concretiza em ações efetivas associadas à sustentabilidade. O comprometimento estratégico com RSC e sustentabilidade é uma importante sinalização da empresa. Apesar de relacionados, RSC e sustentabilidade apresentam distinção (VAN MARREWIJK; WERRE, 2003; CALDELLI; PARMIGIANI, 2004). Sob o enfoque social, RSC é a vontade da empresa de agir de forma responsável perante um amplo grupo de stakeholders 
com os quais se relaciona de forma direta e/ou indireta, e que se beneficiam das suas ações sociais. A estruturação das ações de RSC visa atender às expectativas de distintos stakeholders, o que é bastante complexo uma vez que muitos destes não têm relação direta com a empresa (SHRIVASTAVA, 1995; DAHLSRUD, 2008). Por sua vez, a preocupação com a sustentabilidade está associada à adoção de um conceito filosófico de desenvolvimento sustentável (dimensões social, ambiental e econômica) no seu processo de tomada de decisão, de forma estratégica e contínua, com base em padrões éticos. Neste sentido, preocupações com sustentabilidade são diretamente associadas aos interesses de acionistas, gestores e credores, uma vez que estão relacionadas à continuidade da empresa. $O$ conceito de sustentabilidade empresarial transcende a questão da continuidade da empresa e associa-se à sustentabilidade do planeta e à responsabilidade da organização com as futuras gerações (SCHWARTZ; CARROLL, 2008; LAMARCHE; RUBINSTEIN, 2012). Há, portanto, uma sinergia entre o conceito filosófico de desenvolvimento sustentável adotado, sua integração ao core business da entidade que é a RSC, e a continuidade destes elementos propiciando a sustentabilidade (BRAGA; SILVA; SANTOS, 2015).

\subsection{Divulgação de RSC e Sustentabilidade}

A divulgação de ações de RSC e a importância da sustentabilidade para a empresa têm sido estudadas sob distintos enfoques teóricos que não são excludentes entre si. A Teoria do Disclosure Voluntário propõe que os gestores e/ou as empresas utilizam a discricionariedade em relação à divulgação de informações corporativas e a decisão sobre o grau de sua divulgação (VERRECCHIA, 2001; RUFINO; MACHADO, 2015). Neste contexto, gestores têm o poder de decisão sobre a divulgação de informação adicional, de caráter não financeiro, cuja divulgação não é exigida, mas que podem ser úteis para o processo de avaliação da empresa e de suas perspectivas futuras. Sob este arcabouço teórico, sugere-se que possa haver uma tendência a divulgar-se o que for favorável à empresa como é o caso de RSC (SUTANTOPUTRA, 2009). Esse tipo de divulgação com finalidade de marketing é amplamente criticada por pesquisadores, e, muitos critérios de avaliação nesta área, para alcançar confiabilidade no mercado, instituíram procedimentos de auditoria. Sob o marco da Teoria da Legitimidade, uma empresa está submetida a contratos sociais por meio dos quais se propõe a cumprir ações socialmente desejadas pela sociedade (PATTEN, 1991; BEBBINGTON; LARRINAGA-GONZÁLEZ; MONEVA -ABADÍA, 2008; EUGÉNIO, 2010; PLETSCH et al., 2014). Tais ações de benefício social trazem também retorno para a empresa em termos de legitimação de suas ações e permitindo sua continuidade, sendo sua divulgação um importante instrumento que a empresa dispõe neste processo de legitimação (DEEGAN, 2002). A Teoria da Legitimidade tem ganhado importância na explicação da divulgação de RSC ao mesmo tempo em que se tem apontado necessidade de ampliação da pesquisa em mercados em desenvolvimento considerando que nestes ambientes os stakeholders domésticos têm menos poder e os externos (investidores e consumidores externos, imprensa internacional) passam a ter um papel mais relevante juntamente com o papel regulador do Estado (ALI; FRYNAS; MAHMOOD, 2017; ALI et al., 2018). O enfoque Stakeholder é também uma teoria sócio-política que propõe modelos explicativos do relacionamento entre a empresa e o amplo espectro de stakeholders da mesma. Esta teoria sugere que uma empresa que dá importância a aspectos sociais e/ou de sustentabilidade buscará estabelecer relações de confiança com todos os seus stakeholders, com fundamento em relações leais e justas, e respeitará estes stakeholders e o meio-ambiente (HARRISON; BOSSE; PHILLIPS, 2010; FREEMAN; RUSCONI; SIGNORI , STRUDLER, 2012; BROWN; FORSTER, 2013; TULLBERG, 2013). A Teoria Institucional prevê que o ambiente legal e institucional no qual a organização está inserida, composto por um complexo conjunto de stakeholders, exerce influência sobre a mesma, sendo capaz de 
influenciar em suas políticas e em seu processo de divulgação de informação (DIMAGGIO; POWELL, 1983; BRAMMER; JACKSON; MATTEN, 2012). Segundo esta proposta, a divulgação de RSC estará também diretamente influenciada pelo entorno legal que pode estabelecer regras para a mesma, como a sua obrigatoriedade ou não, ou mesmo as diretrizes de relatórios.

Estes enfoques teóricos tentam explicar o comportamento da empresa relativamente a sua ação de RSC e preocupação com a sustentabilidade, como também a divulgação da atuação da empresa, de certa forma obrigando-a a ir além das exigências legais para serem percebidas como atores responsáveis em suas diversas atuações (GJøLBERG, 2009). De um modo geral, a pesquisa tem encontrado resultados no sentido de que a divulgação de ações de RSC é relevante para o valor da empresa (CLARKSON et al., 2013; PLUMLEE et al., 2015).

A literatura tem documentado evidência de atributos de empresa, bem como de fatores exógenos, que contribuem para a intensidade das ações de RSC, preocupação com a sustentabilidade e com o nível de divulgação de ambos, sob a óptica de distintos enfoques teóricos. Corroborando com as proposições da Teoria Institucional, há resultados indicando que, de fato, o entorno legal e institucional tem influência sobre o grau de atenção dado pela empresa a ações de RSC e a preocupação com sustentabilidade da mesma, bem como com a sua divulgação. Destaca-se, notadamente, o papel do governo e de instituições regulamentadoras (BAUGHN; BODIE; MCINTOSH, 2007; WILLIAMS; AGUILERA, 2008; DOBERS; HALME, 2009; ALON et al., 2010). Adicionalmente, também com evidência documentada, destaca-se a ação de entidades da sociedade civil como os sindicatos, as ONGs, os investidores e os clientes, por exemplo, que tanto podem pressionar aperfeiçoamentos no ambiente institucional quanto podem ter efeito nas ações de RSC da empresa e sua divulgação (MAIGNAN, 2001; FREEMAN; WICKS; PARMAR, 2004; BAUGHN; BODIE; MCINTOSH, 2007; WILLIAMS; AGUILERA, 2008; DE LOS RÍOS BERJILLOS et al., 2012). As questões da legitimação e de preocupação com a reputação e imagem da empresa têm sido consideradas também como capazes de motivar ações de RSC e preocupação com sustentabilidade da empresa. A literatura tem proposto, e já documentado evidência, da preocupação com reputação e legitimação como possível motivação, associada a características da estrutura de propriedade, como possível fator que interfere em políticas de RSC (ROBERTSON, 2009; SEE, 2009; CRISÓSTOMO; FREIRE, 2015; BARAIBAR-DIEZ; SOTORRÍO, 2018).

Sob qualquer enfoque, a divulgação passa a ser um ponto importante, notadamente em mercados que exigem cada dia mais transparência e divulgação da informação para que possa haver uma adequada avaliação da empresa em seu contexto. As formas de divulgação de informações da empresa sobre ações de RSC e sustentabilidade são diversas. A empresa pode fornecer informações sobre RSC separadamente (Relatório de Sustentabilidade) ou em conjunto com o relatório financeiro compondo assim um relatório integrado (GAMERSCHLAG; MÖLLER; VERBEETEN, 2011; BARTH et al., 2017). No Brasil, destacam-se as publicações do Relatório da Administração, da Demonstração do Valor Adicionado (DVA) e do Balanço Social (modelo lbase). Tem sido ampliada a quantidade de métricas para mensuração de RSC e sustentabilidade, apesar da ausência de formalização e de obrigatoriedade de sua divulgação (TSCHOPP; HUEFNER, 2015).

\section{3 Índice de Sustentabilidade Empresarial (ISE) e hipóteses}

Índices de RSC e sustentabilidade foram criados em sintonia com a crescente preocupação com os investimentos socialmente responsáveis. Tais índices são projetados com o objetivo de transmitir aos interessados o grau de preocupação da empresa com RSC e sustentabilidade de modo a facilitar o processo de avaliação de stakeholders externos à empresa como também 
a comparação entre empresas (SKILLIUS; WENNBERG, 1998; STATMAN, 2006; ORSATO; GARCIA; MENDES-DA-SILVA; SIMONETTI, MONZONI, 2015).

O mercado brasileiro, seguindo o modelo de outros países, criou em 2004 o Índice de Sustentabilidade Empresarial (ISE) (BM\&FBOVESPA, 2016). O ISE foi criado pela B3, com o suporte de várias instituições (IBGC; GVces; Instituto Ethos; ABRAPP; APIMEC; Anbid; IBASE, Ministério do Meio Ambiente), sendo o quarto indicador desta natureza no mundo e o primeiro na América Latina que avalia a preocupação da empresa relativamente aos três pilares da sustentabilidade (social, econômico e ambiental) (COLARES et al., 2012).

O Índice de Sustentabilidade Empresarial é uma carteira teórica de aproximadamente 40 empresas, escolhidas entre as mais presentes no mercado e melhor avaliadas em termos de RSC e sustentabilidade no ano que precede a composição da carteira. Esta avaliação da empresa é realizada por meio de um processo conduzido pelo Conselho Deliberativo do Índice de Sustentabilidade Empresarial (CISE) em empresas que satisfazem algumas condições (BM\&FBOVESPA, 2012; 2015): (i) estar entre as 200 empresas com ações mais negociadas nos últimos 12 meses, (ii) ter sido negociada em pelo menos $50 \%$ das sessões do mercado no mesmo período, (iii) concordar com os critérios de sustentabilidade endossados pelo Conselho Deliberativo do ISE. As empresas que satisfazem a estes requisitos respondem, voluntariamente, a um questionário que incorpora sete dimensões (DANTAS et al., 2016; ORIDE; MYSZCZUK, 2017): Dimensão Geral, Dimensão Natureza do Produto, Dimensão Governança Corporativa, Dimensão Econômico-Financeira, Dimensão Ambiental, Dimensão Social e Dimensão Mudanças Climáticas.

Com relação à dimensão ambiental, os questionários são diferenciados por grupos de setores econômicos, visando considerar as especificidades de cada setor quanto a seus impactos ambientais. Cada dimensão tem peso 100 e é subdividida em critérios cujos pesos são definidos pela relevância do tema no contexto atual da gestão empresarial e das demandas da sociedade, sendo privilegiadas as práticas de gestão e o desempenho. O questionário é composto por questões objetivas. O conjunto de questionários é analisado identificando-se grupos de empresas com desempenho social similar e apontando o grupo com melhor desempenho geral. As empresas desse grupo compõem a carteira final do ISE, que é composta por um número máximo de 40 empresas, com no período do primeiro dia útil de janeiro até o último dia útil de dezembro.

A presença no ISE confere visibilidade positiva à empresa. Esta presença é uma forma eficiente e de grande visibilidade que a empresa tem para demonstrar seu grau de preocupação com questões sociais e de sustentabilidade que dão suporte a seu objetivo de legitimação de suas práticas empresariais (DEEGAN, 2002). Estar no ISE sinaliza ao conjunto de stakeholders alto nível de compromisso da empresa com as questões de RSC e sustentabilidade. Tal visibilidade positiva constitui-se fator de atração do ISE para empresas buscarem elevado padrão de reputação como também de legitimar suas ações frente à sociedade. Conforme proposto pela Teoria da Legitimação, empresas tendem a ter este interesse, o que seria um forte fator de interesse em figurar no ISE. O caráter de voluntariedade no processo seletivo do ISE também é relevante porque o mercado sabe do caráter voluntário da empresa na participação no processo seletivo do ISE e, assim, empresas que ali estão seriam aquelas que, em princípio, empreenderam RSC e estão interessadas em divulgar tais ações. Aqui, trata-se exatamente de participação voluntária em um processo que tem potencial para contribuir para a legitimação da empresa uma vez que envolve avaliação detalhada de ações socioambientais da empresa com a divulgação, também de forma opcional por parte da empresa, do conteúdo do questionário da mesma. Assim, surge aqui uma combinação da Teoria da Divulgação Voluntária com a Teoria da Legitimação que tem sua importância sobre a divulgação de RSC documentada (MICHAELS; GRÜNING, 2018). 
Este conjunto de fatores motiva a proposição de que o interesse em figurar no ISE tem sido crescente desde a sua criação. Esta atratividade do ISE como instrumento de divulgação com alto poder de visibilidade para a empresa com reflexos positivos para sua reputação, imagem e legitimação ampara a seguinte hipótese:

\section{Hipótese 1: Empresas são persistentes em manter-se no ISE.}

Adicionalmente, a empresa pode somar a esta visibilidade obtida por estar no ISE um elemento a mais que é a disponibilização pública das suas respostas ao questionário ISE. Esta situação foi facultada às empresas em 2012. O Conselho Deliberativo do ISE facultou às empresas que viessem a compor o ISE, a disponibilização pública das suas respostas ao questionário ISE (BM\&FBOVESPA, 2015). O Conselho Deliberativo do ISE argumentou estar atendendo à crescente demanda do mercado e da sociedade por mais transparência sobre as ações de RSC e de sustentabilidade das empresas. Esta situação está relacionada com o enfoque Stakeholder ao haver uma suposta demanda por estas informações por parte do mercado e da sociedade. Por outro lado, também se vê uma relação direta com o disclosure voluntário e a propensão de divulgação de notícias favoráveis (VERRECCHIA, 2001; RUFINO; MACHADO, 2015), uma vez que a empresa fica em situação confortável ao saber que só será divulgada a informação caso ela venha a compor o índice. $O$ fato é que ao fazer tal divulgação a empresa somará aspecto positivo a sua imagem. Desta forma, a empresa, ao saber que ganhará pontos em sua imagem ao divulgar o conteúdo do questionário, e que a divulgação estará condicionada a sua classificação dentre as que comporão o índice, ela terá interesse em fazê-lo. Esta argumentação motiva a proposição da hipótese de adesão à divulgação voluntária do questionário nos seguintes termos:

Hipótese 2: Empresas estão adotando, de forma continuada, a prática de permitir a divulgação de suas respostas aos questionários anuais do ISE.

\section{METODOLOGIA DE PESQUISA}

\subsection{Amostra}

A amostra analisada é composta pelo universo de todas as 72 (setenta e duas) empresas que já foram listadas no Índice de Sustentabilidade Empresarial (ISE) ao longo do período 2005-2015, pelo menos em um exercício. Este período permite avaliar a persistência das empresas em estar listadas no ISE como também a divulgação do questionário que foi facultada às empresas a partir de 2012.

\subsection{Metodologia}

Esta pesquisa classifica-se como quantitativa, quanto à abordagem, considerando que os dados são organizados, tabulados e submetidos ao cálculo métricas estatísticas de tendência central e de dispersão além de testes de significância (RICHARDISON, 1999; MARTINS; THEÓPHILO, 2009).

Os métodos de procedimento adotados foram: a pesquisa bibliográfica e a documental, utilizando-se os questionários divulgados pelas empresas. Foi realizada uma análise detalhada do questionário ISE, desde a sua primeira edição em 2005. A coleta de dados utilizou-se da técnica de análise de conteúdo, e a análise dos dados inicia-se com a técnica de análise descritiva que permite avaliar o panorama das empresas que já figuraram na carteira ISE, dos setores de 
atuação destas, e a evolução da adesão ao ISE pelo grupo de empresas utilizando-se de gráficos e tabelas (RICHARDISON, 1999).

A avaliação da persistência da empresa em manter-se na carteira ISE, como também da divulgação das respostas ao questionário da empresa, foi realizada por análise descritiva e reforçada por testes de diferença de proporções. $O$ teste de persistência é feito aplicando-se um método não paramétrico utilizado em pesquisa sobre persistência de desempenho de fundos de investimento (BROWN; GOETZMANN, 1995; MALKIEL, 1995; CIRIACO FERNÁNDEZ; SANTAMARÍA AQUILUÉ, 2005). O método consiste na observação anual de todas as empresas que compuseram a carteira ISE, registrando-se a sua situação de estar presente ou não no ISE em cada ano, no período de 2005 a 2015. Desta forma, é possível verificar a presença da empresa no ISE em períodos consecutivos. A observação da presença da empresa por dois períodos consecutivos permite a elaboração de uma tabela de contingência que contém o número de ocorrências a cada dois períodos consecutivos das possíveis situações da empresa: (i) empresa estava no período passado e está no período atual (EE), (ii) empresa não estava no período passado e não está no período atual (NN), (iii) empresa estava no período passado e não está no período atual (EN) e (iv) empresa não estava no período passado e está no período atual (NE). A hipótese da persistência é aceita se o número de observações que indicam repetição de situação (EE e NN) for significativamente superior às observações que indicam mudança de situação quanto à presença no ISE (EN e NE).

Para o cálculo da relação entre as combinações de persistência das empresas foi realizado um teste baseado no Cross-Product Ratio (CPR) (Equação 1).

$$
C P R=\frac{(E E * N N)}{(E N * N E)}
$$

O valor do CPR superior a 1 (um) indica a predominância de empresas observadas em repetição de situação (EE e NN) relativamente à frequência de mudança de situação, sugerindo que há a persistência das empresas, enquanto o valor do CPR abaixo de 1 (um) indica a predominância de mudança de situação (EN ou NE), descartando assim a hipótese de persistência. A verificação da significância estatística do CPR é feita com a aplicação de um teste Z (BROWN; GOETZMANN, 1995; MALKIEL, 1995; CIRIACO FERNÁNDEZ; SANTAMARÍA AQUILUÉ, 2005). A estatística $Z$ (Equação 2), sob a hipótese nula de ausência de persistência, segue uma distribuição Normal padrão.

$$
Z=\frac{\operatorname{Ln}(C P R)}{\sigma[\operatorname{Ln}(C P R)]} \rightarrow N(0,1)
$$

Sendo:

$$
\begin{aligned}
& \operatorname{Ln}(C P R)=\operatorname{Ln}\left[\frac{E E * N N}{E N * N E}\right] \\
& \sigma[\operatorname{Ln}(C P R)]=\sqrt{\frac{1}{E E}+\frac{1}{N N}+\frac{1}{N E}+\frac{1}{E N}}
\end{aligned}
$$


Adicionalmente, de modo a permitir reforço e robustez dos resultados, foi aplicado um teste do chi-quadrado $\left(\chi^{2}\right)$, sendo o $\chi^{2}$ de teste calculado de acordo com a Equação 3, seguindo relevante literatura prévia (KAHN; RUDD, 1995; AGARWAL; NAIK, 2000; HUIJ; VERBEEK, 2007).

$$
X^{2}=\left[\frac{\left(E E-d_{1}\right)^{2}}{d_{1}}\right]+\left[\frac{\left(E N-d_{2}\right)^{2}}{d_{2}}\right]+\left[\frac{\left(N E-d_{3}\right)^{2}}{d_{3}}\right]+\left[\frac{\left(N N-d_{4}\right)^{2}}{d_{4}}\right]
$$

Sendo:

$$
\begin{aligned}
& d_{1}=\frac{(E E+E N) \cdot(E E+N E)}{n} \\
& d_{2}=\frac{(E E+E N) \times\left(E N+N N_{-}^{*}\right.}{n} \\
& d_{3}=\frac{(N E+N N) \cdot(E E+N E)}{n} \\
& d_{4}=\frac{(N E+N N) \cdot(E N+N N)}{n} \\
& n=E E+E N+N E+N N
\end{aligned}
$$

Com relação à hipótese de persistência da divulgação do questionário por parte das empresas que compuseram a carteira ISE desde 2012, foi adotada a mesma metodologia. O método baseia-se na observação anual de todas as empresas que permitiram a divulgação do questionário, registrando-se a sua situação de permitir ou não tal divulgação em cada ano, no período de 2012 a 2015. Desta forma, é possível verificar a situação de divulgação do questionário em períodos consecutivos, o que permite a elaboração de uma tabela de contingência que contém o número de ocorrências a cada dois períodos consecutivos das possíveis situações da empresa: (i) empresa divulgou no período passado e divulga no período atual (AA), (ii) empresa não divulgou no período passado e não divulga no período atual (NN), (iii) empresa divulgou no período passado e não divulga no período atual (AN) e (iv) empresa não divulgou no período passado e divulga no período atual (NA).

\section{RESULTADOS}

A análise da composição do questionário ISE é relevante para permitir conhecer as dimensões de RSC e sustentabilidade que estão sendo avaliadas no processo de seleção do ISE, e 
em que proporção tais dimensões estão sendo consideradas (seção 2.3): Dimensão Geral, Dimensão Natureza do Produto, Dimensão Governança Corporativa, Dimensão Econômico-Financeira, Dimensão Ambiental, Dimensão Social e Dimensão Mudanças Climáticas. Realizou-se uma avaliação anual da proporção de cada dimensão constante no questionário aplicado pelo Conselho Deliberativo do ISE desde seu início em 2005 até 2015.

O Gráfico 1 mostra a distribuição de questões do questionário ISE por dimensão. Observe-se que a dimensão Mudanças Climáticas foi incorporada ao questionário a partir de 20102011, conferindo ainda mais relevância à questão da relação da empresa com o meio ambiente. Como se pode observar há uma relativa manutenção da proporção das dimensões no questionário, principalmente a partir de 2011. A Dimensão Social é a que tem maior representatividade no questionário, sendo contemplada por $24 \%$ do mesmo no primeiro ano (2005-2006) e chegando a representar, aproximadamente, 15\%, em 2014-2015. Por sua vez, a Dimensão Natureza do Produto teve um crescimento no mesmo período, de 2,7\% para mais de 5\% em 2014-2015. É importante mencionar a relevância da Dimensão Governança Corporativa, que representa aproximadamente $10 \%$ do questionário, é a segunda maior dimensão contemplada pelo questionário ISE, demonstrando a importância dada à Governança Corporativa. A seguir, encontram-se as dimensões Geral e Ambiental, compondo, individualmente, quase $9 \%$ do questionário. A Dimensão Econômico-Financeira ocupa aproximadamente $5,8 \%$ do questionário, tendo proporção equivalente à da Natureza do Produto a partir de 2008-2009. Por fim, a Dimensão Mudanças Climáticas, cuja avaliação foi iniciada no questionário de 2010-2011, teve sua presença no questionário elevada de 3,7\%, no primeiro ano, para 4,5\%, em 2015.

Gráfico 1 - Distribuição do questionário ISE por dimensão no período 2005-2015.

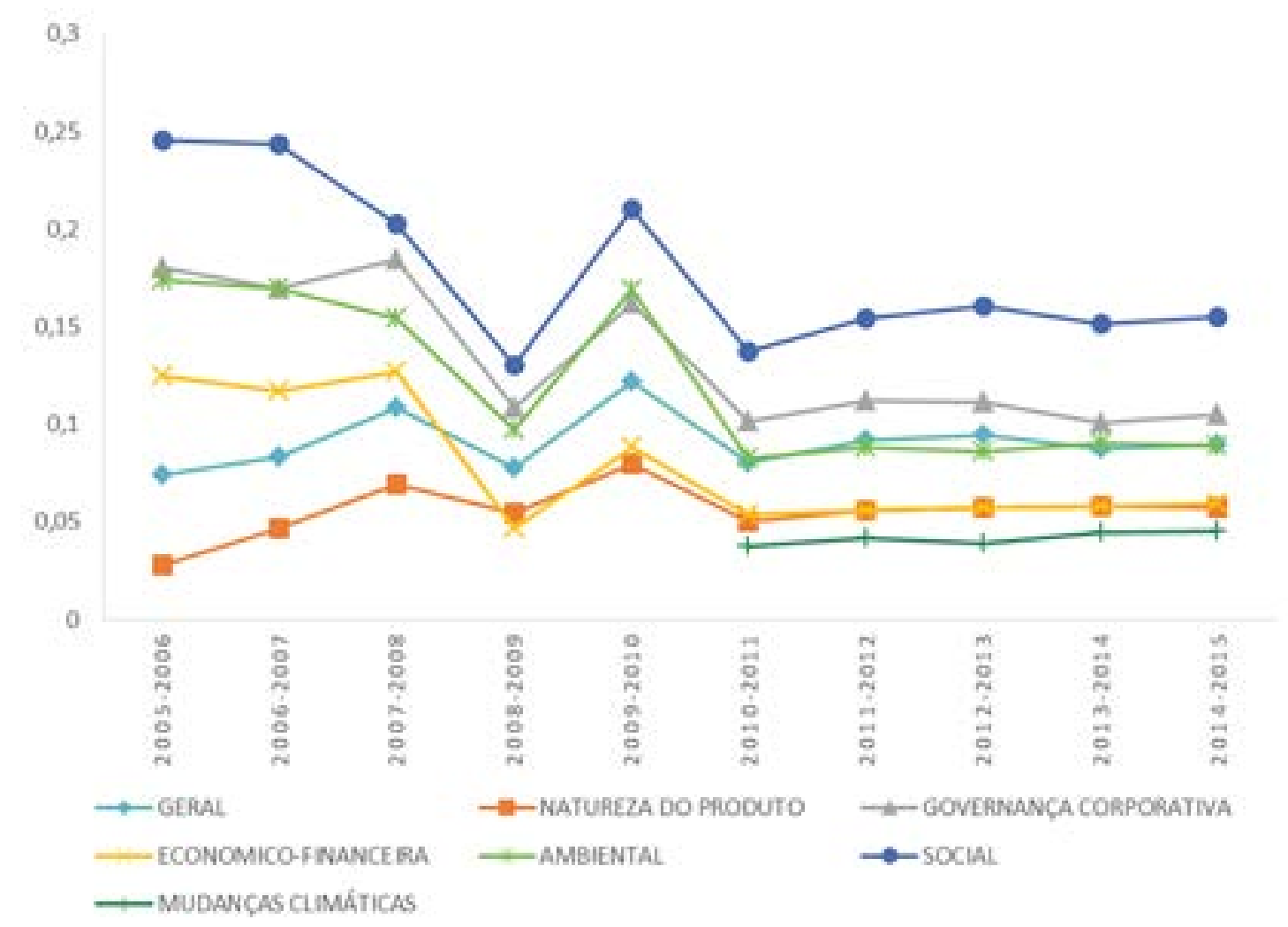

Fonte: Dados da pesquisa. 
O Gráfico 2 apresenta a evolução do número de empresas convidadas para participar do ISE através do envio do questionário, a evolução do número de empresas respondentes, e do número de empresas selecionadas. Observa-se que, ao longo do período 2005-2015, houve uma relevante ampliação do número de empresas convidadas em função do objetivo de maior divulgação do ISE. Entretanto, houve um tênue decréscimo no número de empresas respondentes, o que pode ser explicado por reconhecimento de eventual baixo potencial competitivo por parte empresa diante das que questões que lhes são apresentadas no questionário a ela apresentado. Quanto ao número de empresas que compõem a carteira observa-se que houve um crescimento, atingindo-se o limite de 40 em 2014, que se mantém até 2015.

Gráfico 2 - Evolução da adesão das empresas ao ISE no período 2005-2015.

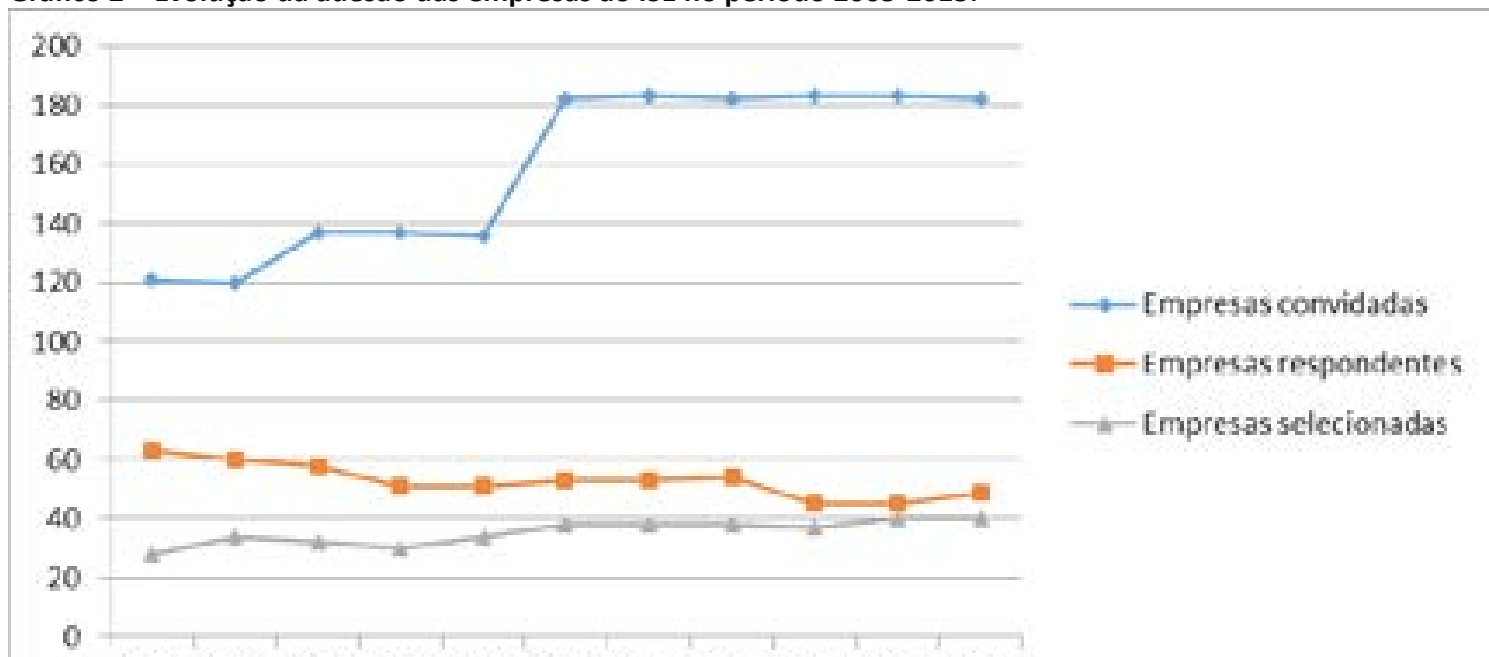

20052006200720082009201020112012201320142015

Fonte: Dados da pesquisa.

A Tabela 1 exibe a distribuição da quantidade de empresas, classificadas por setor econômico, que já participaram da carteira do ISE em pelo menos um ano. Pode-se observar que empresas de todos os setores da economia no Brasil já participaram do ISE, o que demonstra sua importância como um canal de divulgação do grau de RSC e sustentabilidade que, de fato, parece estar despertando o interesse das empresas. O setor Materiais Básicos (Siderurgia e Metalurgia, Papel e Celulose, Petroquímicos e Minerais Metálicos) é o mais frequente na composição do ISE (23,61\%). O setor de Utilidade Pública (Energia Elétrica, Água e Saneamento, e Gás) ocupa a segunda maior proporção de empresas que já figuraram no ISE (19,44\%). Ambos os setores, Materiais Básicos e Utilidade Pública, são considerados pela Lei 10.165/2000 como de elevado impacto ambiental, o que pode gerar uma maior pressão para que estas empresas preocupem-se mais com a divulgação da RSC e sustentabilidade (CRISÓSTOMO; SOUZA; PARENTE, 2012; VIANA JUNIOR; CRISÓSTOMO, 2017). Além desta mais elevada pressão por ações socioambientais, empresas de setores potencialmente agressivos ao meio ambiente podem ser mais motivadas à busca por legitimação de suas atividades (HEATH; LEE, 2016), podendo-se constituir a presença no ISE um importante instrumento neste sentido. 
Tabela 1 - Distribuição de frequência dos setores que já compuseram o ISE no período 2005-2015.

\begin{tabular}{ccc}
\hline Setor & Número de observações & Percentual \\
\hline Bens Industriais & 4 & $5,56 \%$ \\
Construção e Transporte & 7 & $9,72 \%$ \\
Consumo Cíclico & 5 & $6,94 \%$ \\
Consumo Não Cíclico & 7 & $9,72 \%$ \\
Financeiro e Outros & 12 & $16,67 \%$ \\
Materiais Básicos & 17 & $23,61 \%$ \\
Petróleo, Gás e Biocombustíveis & 1 & $1,39 \%$ \\
Telecomunicações & 5 & $6,94 \%$ \\
Utilidade Pública & 14 & $19,44 \%$ \\
\hline Total & 72 & $100,00 \%$ \\
\hline
\end{tabular}

Fonte: Dados da pesquisa.

A Tabela 2 exibe a distribuição de frequência do número de vezes que uma empresa fez parte da carteira do ISE no período 2005-2015. Observa-se que 19,44\% das empresas figuraram no ISE somente em um exercício. Isto significa que a grande maioria da empresas, $80,56 \%$, figuraram no índice em 2 ou mais anos. Das empresas que já estiveram listadas no ISE, 48,61\% delas compuseram o índice em 5 ou mais anos. Estes resultados são um forte indício de um aumento no número de empresas que permaneceram no ISE em anos consecutivos, sendo esta realidade um sinal de interesse das empresas em permanecer na carteira ISE. Figurar no ISE sinaliza preocupação da empresa com questões socioambientais e, a presença no índice em anos consecutivos pode contribuir para transmitir ao mercado o alto grau de preocupação com estas questões e a possível consistência da empresa em sua política de RSC e de sustentabilidade.

Tabela 2 - Distribuição de frequência do número de vezes que a empresa compôs o ISE no período 2005-2015

\begin{tabular}{|c|c|c|}
\hline $\begin{array}{l}\text { N vezes } \\
\text { no ISE }\end{array}$ & Número de empresas que apareceram $\mathrm{N}$ vezes no ISE & $\%$ \\
\hline 1 & $\begin{array}{l}14 \text { (ACESITA, AM INOX, ARCELOR, B2W DIGITAL, BELGO MINEIRA, COPESUL, JSL, LOCA- } \\
\text { LIZA, LOJAS AMERICANAS, LOJAS RENNER, ODONTOPREV, OI, TAM, USIMINAS) }\end{array}$ & 19,44 \\
\hline 2 & $\begin{array}{l}11 \text { (ALL AMER LAT, ANHANGUERA, CIELO, FLEURY, GOL, INDS ROMI, KLABIN, PETRO- } \\
\text { BRAS, SADIA, SUZANO PETRO, VIVO) }\end{array}$ & 15,28 \\
\hline 3 & 6 (ARACRUZ, CELESC, IOCHP-MAXION, REDECARD, TELEFONICA BRASIL, UNIBANCO) & 8,33 \\
\hline 4 & 6 (COPASA, ECORODOVIAS, ITAUBANCO, PERDIGAO, ULTRAPAR, VCP) & 8,33 \\
\hline 5 & 6 (BIC BANCO, DASA, SANTANDER BR, TELEMAR, VALE, WEG) & 8,33 \\
\hline 6 & 5 (BRF SA, EVEN, FIBRIA, ITAUUNIBANCO, SUL AMERICA) & 6,94 \\
\hline 7 & 3 (CCR SA, DURATEX, TIM PART S/A) & 4,17 \\
\hline 8 & 5 (AES TIETE, CESP, ITAUSA, LIGHT SA, SABESP) & 6,94 \\
\hline 9 & $\begin{array}{l}8 \text { (COELCE, COPEL, ELETROBRAS, EMBRAER, ENERGIAS BR (EDP), GERDAU, GERDAU } \\
\text { MET, SUZANO PAPEL) }\end{array}$ & 11,11 \\
\hline 10 & $\begin{array}{l}8 \text { (AES ELETROPAULO, BCO BRASIL, BRADESCO, BRASKEM, CEMIG, CPFL ENERGIA, NA- } \\
\text { TURA, TRACTEBEL) }\end{array}$ & 11,11 \\
\hline Total & 72 & 100,00 \\
\hline
\end{tabular}

Nota: $\mathrm{N}$ indica o número de vezes que a empresa compôs a carteira ISE. Fonte: Dados da pesquisa. 
Conforme relatado na seção de aspectos metodológicos desta pesquisa, procedeu-se à avaliação da persistência da empresa na composição da carteira ISE. O Gráfico 3 apresenta a evolução das situações das empresas quanto à presença das empresas no ISE em dois períodos consecutivos como mencionado na seção 3.2: (i) empresa estava no período passado e está no período atual (EE), (ii) empresa não estava no período passado e não está no período atual (NN), (iii) empresa estava no período passado e não está no período atual (EN) e (iv) empresa não estava no período passado e está no período atual (NE).

Pode-se observar que o número de empresas que não aderiram ao índice por dois anos consecutivos (NN) decresceu de 33 casos em 2006-2007 para 28 em 2014-2015. Por outro lado, houve um aumento das situações de empresas que permanecem no índice em dois anos consecutivos (EE), atingindo 36 no biênio 2014-2015. Este resultado é um forte indício do elevado interesse das empresas em permanecerem no ISE.

Gráfico 3 - Persistência das empresas na carteira ISE

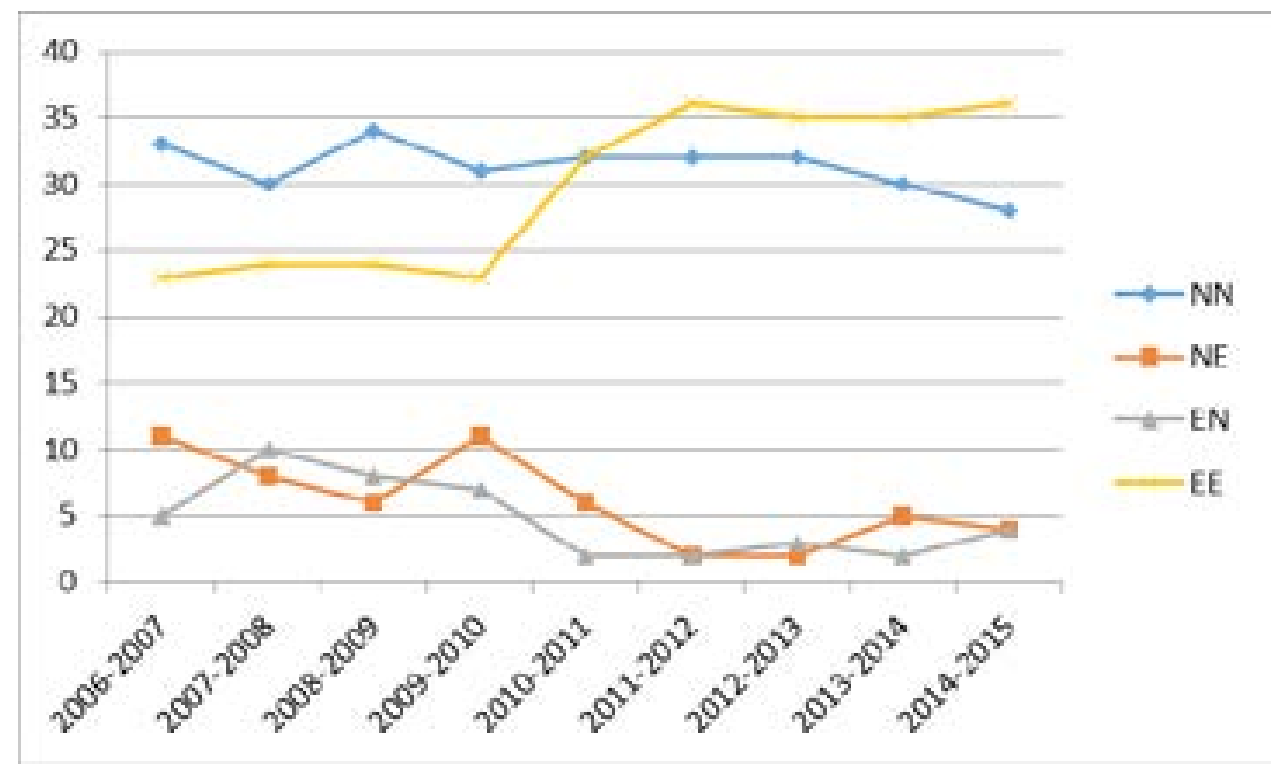

Nota: $\mathrm{NN}$ = empresa não estava no ISE no período passado e não está no período atual; $\mathrm{EE}$ = empresa estava no período passado e está no período atual; $\mathrm{EN}$ = empresa estava no período passado e não está no período atual; $\mathrm{NE}=\mathrm{empresa}$ não estava no período passado e está no período atual.

Fonte: Dados da pesquisa.

Além da análise descritiva, aplicou-se também um teste de diferença de proporções, conforme apresentado na seção 3.2. Para a realização do teste observa-se o número de situações de cada empresa em dois anos consecutivos e gera-se a tabela de contingência com a contagem do número de situações para dois períodos consecutivos (Tabela 3).

Tabela 3 - Frequência de situações de presença no ISE em 2 anos consecutivos

\begin{tabular}{cccc}
\hline & & \multicolumn{2}{c}{ Situação da empresa no ano atual } \\
\cline { 2 - 3 } & & $\begin{array}{c}\text { Empresa não está no ISE } \\
(\mathrm{N})\end{array}$ & $\begin{array}{c}\text { Empresa está no ISE } \\
\text { (E) }\end{array}$ \\
\hline $\begin{array}{c}\text { Situação da } \\
\text { empresa no ano } \\
\text { anterior }\end{array}$ & Empresa não está no ISE (N) & $282(\mathrm{NN})$ & $43(\mathrm{NE})$ \\
\cline { 2 - 4 } & Empresa está no ISE (E) & $55(\mathrm{EN})$ & $268(\mathrm{EE})$ \\
\hline
\end{tabular}

Fonte: Dados da pesquisa. 
A partir da tabela de contingência calcula-se o Cross Product Ratio (CPR) e as estatísticas de teste $Z$ e $\chi^{2}$. O teste $\mathbf{z}$ foi significativo $(z=15,7$; valor- $p=0,000)$, indicando que, de fato, há uma diferença de proporção na situação das empresas com relação à presença na carteira do ISE, como sugerido na Hipótese 1 , sendo mais elevadas as proporções de situações de repetição de situação. Este resultado é também confirmado pelo teste $\chi^{2}\left(\chi^{2}=315,7\right.$; valor-p $\left.=0,000\right)$. Observese a alta proporção de situações que correspondem à presença no índice em anos consecutivos (EE), num total de 268 , aproximadamente $41,4 \%$ das ocorrências, e a proporção de situações que correspondem à ausência no índice em anos consecutivos (NN), aproximadamente $43,5 \%$ das ocorrências. A situação de permanência no índice em dois anos consecutivos $(41,4 \%)$ é de fato relevante pois demonstra o interesse da empresa em permanecer no índice ao envidar esforços em busca de melhor padrão de RSC.

Este resultado converge com a argumentação da Hipótese 1 que preconiza haver interesse por parte das empresas em estar presentes e permanecer na carteira ISE em função de possíveis benefícios advindos desta presença, tais como: a transmissão ao conjunto de stakeholders da mensagem de que empresa tem elevado padrão de preocupação socioambiental como resposta às demandas destes (MCVEA; FREEMAN, 2005), a visibilidade positiva que favorece os interesses de legitimação das empresas (DEEGAN, 2002), e o fato de participar voluntariamente no processo de seleção e figurar voluntariamente no índice que funciona como um processo de divulgação voluntária do grau de preocupação com questões socioambientais. Desta forma, o interesse por legitimação obtida por meio da participação em um processo que permite a divulgação voluntária do nível de atenção dado pela empresa a questões socioambientais mostra que, de fato, parece haver uma combinação da Teoria da Divulgação Voluntária com a Teoria da Legitimação como considerado na literatura (MICHAELS; GRÜNING, 2018). Também merece menção a possível presença de um efeito "lock in" como estimulador da permanência da empresa no ISE uma vez que a empresa, ao sair do índice, pode transmitir uma mensagem negativa sobre seus esforços relativos a ações socioambientais, o que a empresa deve querer evitar (ORSATO; GARCIA; MENDES-DA-SILVA; SIMONETTI , MONZONI, 2015).

O outro aspecto relevante avaliado está associado à questão da permissão, por parte da empresa, para divulgação do conteúdo de suas respostas ao questionário ISE. Avaliar o interesse das empresas em tornar públicas estas respostas é um indicativo de avanço no interesse pela divulgação de tais informações que pode ser sinal de busca de melhoria em imagem e reputação além de legitimação das atividades da empresa. A Tabela 4 exibe o número de companhias que autorizaram a divulgação de suas respostas e suas respectivas proporções de 2012 a 2015. No ano de 2012, 8 das 38 empresas constituintes da carteira daquele ano, ou seja, 21,05\%, autorizaram a divulgação de seus questionários. Esse número cresceu para 37,84\% em 2013, 55\% em 2014 e destacou-se em 2015 com 85\%, o que é um forte sinal de uma tendência à divulgação dos questionários e consequentemente melhoria da transparência das empresas.

Tabela 4 - Proporção de empresas que autorizaram a divulgação do questionário ISE, 2012-2015

\begin{tabular}{lcccc}
\hline & \multicolumn{4}{c}{ Ano de autorização da divulgação } \\
\cline { 2 - 5 } & 2012 & 2013 & 2014 & 2015 \\
\hline \multicolumn{1}{c}{ Empresas que compõem o ISE } & 38 & 37 & 40 & 40 \\
\hline $\begin{array}{l}\text { Empresas que compunham o ISE e autorizaram divul- } \\
\text { gação do questionário }\end{array}$ & $8(21,05 \%)$ & $14(37,84 \%)$ & $22(55 \%)$ & $34(85 \%)$ \\
\hline
\end{tabular}

Fonte: Dados da pesquisa. 
No Gráfico 4 tem-se a evolução das situações das empresas quanto à autorização da divulgação do questionário em dois períodos consecutivos, por parte das empresas que compõem o ISE, como mencionado na seção 3.2: (i) empresa autorizou a divulgação no período passado e autoriza no período atual (AA), (ii) empresa não autorizou no período passado e não autoriza no período atual (NN), (iii) empresa autorizou no período passado e não autoriza no período atual (AN) e (iv) empresa não autorizou no período passado e autoriza no período atual (NA). Observa-se que o número de empresas que não autoriza divulgação do questionário por dois anos consecutivos (NN) decresceu de 58 no biênio 2012-2013 para 37 no período 2014-2015. No entanto, houve um incremento relevante na situação de autorização de divulgação em dois anos consecutivos (AA) que se inicia com 8 empresas no biênio 2012-2013 e atinge 21 no período 2014-2015. Esta elevação da frequência de empresas que autorizam a divulgação de questionário em anos consecutivos é mais um forte indício da tendência de mais ampla divulgação de ações socioambientais e mais transparência, algo que tem sido destacado como relevante pelas Normas Internacionais de Contabilidade.

Gráfico 4 - Persistência de divulgação dos questionários respondidos no ISE

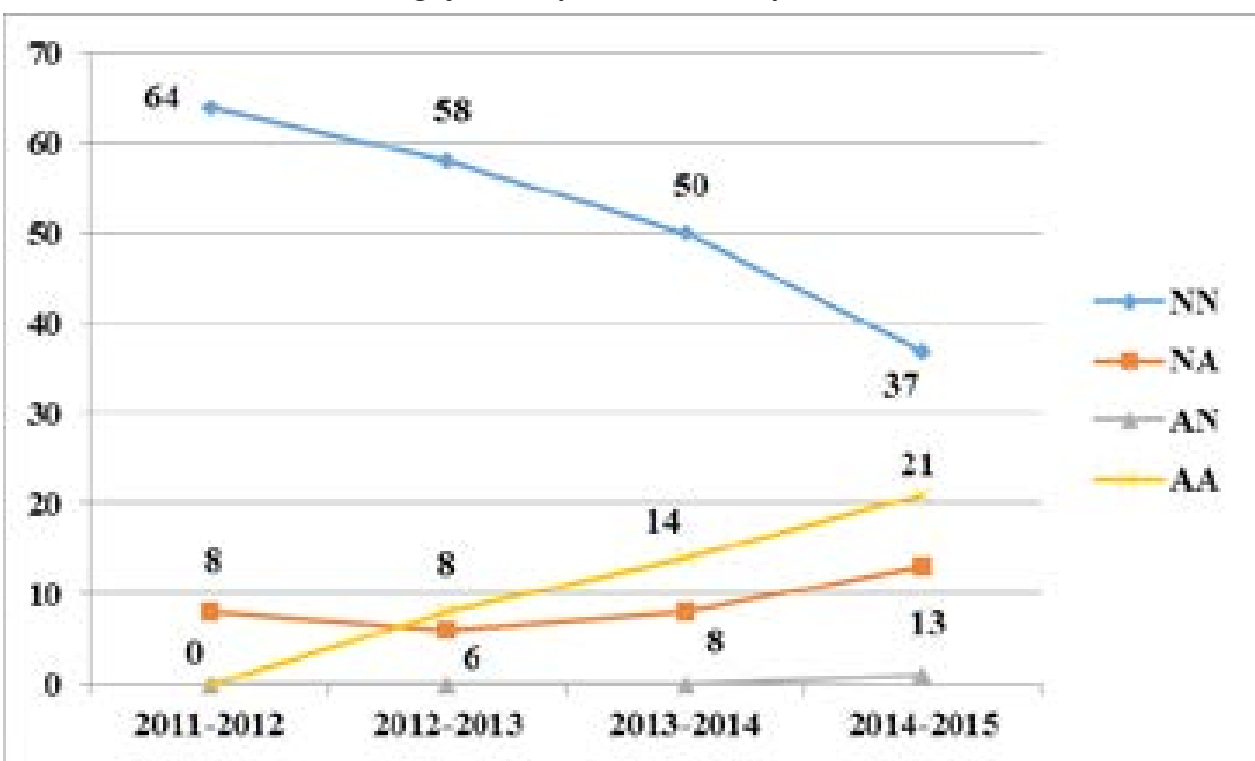

Nota: NN = empresa não autorizou divulgação do questionário no período passado e não está no período atual; NA = empresa não autorizou no período passado e autoriza no período atual; $A N$ = empresa autorizou no período passado e não autoriza no período atual; $A A$ = empresa autorizou no período passado e autoriza no período atual.

Fonte: Dados da pesquisa.

Além desta análise descritiva, fez-se um teste de diferença de proporções, conforme apresentado na seção 3.2. Para calcular a estatística de teste, compõe-se uma tabela de contingência que contém a contagem do número de situações de autorização do questionário para dois anos consecutivos (Tabela 5). Foram considerados os biênios 2012-2013, 2013-2014 e 20142015, uma vez que só em 2012 foi feita a primeira autorização de divulgação dos questionários. Esta é a razão para o número de situações AA (empresa autorizou a divulgação no período passado e autoriza no período atual) ser igual a zero no Gráfico 4 no biênio 2011-2012, pois no ano de 2011 não havia esta divulgação. 
Tabela 5 - Frequência de situações de autorização de divulgação do questionário ISE em anos consecutivos

Situação de divulgação das respostas da empresa ao questionário no ano atual

Empresa não autoriza (N) Empresa autoriza (A)

\begin{tabular}{lccc}
\hline $\begin{array}{c}\text { Situação de divulgação } \\
\text { do questionário no ano } \\
\text { anterior }\end{array}$ & Empresa não autorizou (N) & 145 (NN) & 27 (NA) \\
\cline { 2 - 3 } & Empresa autorizou (A) & 1 (AN) & 43 (AA) \\
\hline
\end{tabular}

Fonte: Dados da pesquisa.

A partir desta tabela de contingência (Tabela 5) calcula-se o Cross Product Ratio (CPR). $O$ teste $\mathbf{z}$ foi significativo $(z=5,27$; valor- $p=0,000)$, indicando que, de fato, há uma diferença de proporção na situação das empresas com relação à divulgação das respostas da empresa ao questionário, sendo mais elevadas as proporções de situações de manutenção de situação com relação à divulgação. Este resultado é também confirmado pelo teste $\chi^{2}\left(\chi^{2}=107,63\right.$; valor- $p=$ $0,000)$. Verifica-se que há uma alta proporção de situações que correspondem à autorização de divulgação do questionário em anos consecutivos (AA), no total de 43, e a proporção de situações que correspondem à não autorização de divulgação (NN) (145). Esta elevada ausência de autorização em dois anos consecutivos deve-se ao fato de que há um grande contingente de empresas que participou do índice poucas vezes. Deste modo, observa-se que, de fato, há uma mais elevada ocorrência da situação de repetição da autorização de divulgação do questionário comparando-se à situação de mudança de postura da empresa relativamente a esta permissão, como proposto pela Hipótese 2.

A possibilidade de permissão da divulgação do conteúdo do questionário respondido pela empresa ao longo do período da pesquisa é um mecanismo adicional de que dispõe a empresa para demonstrar mais transparência em sua conduta no que se refere à preocupação com ações socioambientais. Permitir esta divulgação constitui-se importante ação de divulgação voluntária que a empresa pode estar usando com o objetivo de obtenção de legitimação e melhorar sua imagem como empresa socialmente responsável. Ao divulgar tais informações, a empresa estará realizando uma ação de divulgação adicional que pode estar na direção do atendimento de demandas do coletivo de stakeholders da empresa por mais informação, como prevê o enfoque Stakeholder (VERRECCHIA, 2001; RUFINO; MACHADO, 2015).

\section{CONSIDERAÇÕES FINAIS}

A importância da sustentabilidade para a empresa e a divulgação de ações de RSC têm sido abordadas sob distintos arcabouços teóricos. Esta pesquisa faz uma análise do Índice de Sustentabilidade Empresarial (ISE) e da adesão das empresas ao mesmo a partir de uma construção sobre as propostas do enfoque Stakeholder, da Teoria da Legitimidade e da Teoria da Divulgação Voluntária, que buscam explicar o comportamento da empresa com relação à sua política de RSC e respectiva divulgação de ações desenvolvidas nesta área.

Este trabalho tem como objetivo analisar, a partir da avaliação da adesão ao Índice de Sustentabilidade Empresarial (ISE) e da persistência da presença das empresas no referido índice, como também da divulgação voluntária das respostas aos questionários, o interesse das empresas em divulgar sua estratégia e ações relativas à Responsabilidade Social e Sustentabilidade por meio da presença no ISE. Para atingir este objetivo, faz-se uma análise do questionário ISE por 
meio da mensuração da proporção das dimensões, ou áreas, que são abordadas pelo mesmo. Realiza-se uma análise da adesão e da persistência das empresas no ISE, e do nível de persistência de divulgação dos questionários respondidos pelas empresas participantes do ISE.

A análise do questionário ISE que é enviado às empresas permite observar-se que sete dimensões, ou áreas de ação da empresa, são contempladas, aí estando: Dimensão Geral, Dimensão Natureza do Produto, Dimensão Governança Corporativa, Dimensão Econômico-Financeira, Dimensão Ambiental, Dimensão Social e Dimensão Mudanças Climáticas. Esta gama de dimensões mostra a complexidade envolvida nesta avaliação. Quanto à distribuição das questões por dimensão, observa-se uma maior proporção de questões relativas à dimensão social, seguida pela dimensão governança corporativa. A relevância dada à dimensão Governança Corporativa mostra a importância que tem sido dada a esta questão, que está muito associada à continuidade do negócio e à dimensão econômico-financeira que também tem alta proporção no questionário.

Os resultados indicam que, de fato, houve um crescimento na adesão ao Índice de Sustentabilidade Empresarial e no número de empresas que compõem o índice em anos consecutivos, sinalizando o interesse na permanência no mesmo. Estes números são fortes indícios do interesse crescente das empresas em integrar a carteira do ISE como previsto pela Hipótese 1 que sugere que empresas são persistentes em manter-se no ISE. Em relação à persistência da divulgação das respostas ao questionário ISE, os resultados mostram que houve também um crescimento da permissão de divulgação correspondendo o sugerido pela Hipótese 2 que preconiza que as empresas estão adotando, de forma continuada, a prática de permitir a divulgação de suas respostas aos questionários anuais do ISE. A proporção de companhias que autorizam a divulgação de suas respostas saltou de 21,05\% em 2012 para 85\% em 2015, indicando uma forte tendência de divulgação dos questionários.

Estes achados mostram que, de fato, parece haver interesse das empresas em participar do ISE. Tal interesse pode ser visto como uma forma que a empresa encontra para demonstrar que considera relevante seu relacionamento com um amplo espectro de stakeholders como previsto pelo enfoque Stakeholder. Ao compor o ISE, a empresa está sinalizando que tem um alto grau de preocupação com os stakeholders da empresa, contemplados nas sete dimensões do questionário ISE. Ao mesmo tempo, ao querer demonstrar esta preocupação, a empresa pode também estar considerando o ISE como um importante instrumento de melhoria da sua imagem e reputação, e de legitimação de suas ações, o que está associado à proposta da Teoria da Legitimação das ações da empresa. Por fim, o caráter de voluntariedade de todo o processo de participação no ISE encontra associação com as proposições da Teoria da Divulgação Voluntária, a qual prevê o interesse da empresa em divulgar notícias positivas, o que ajuda no processo de legitimação e de melhoria de imagem. No caso do ISE, esta parece ser uma oportunidade singular, uma vez que a empresa só terá exposição positiva ao figurar no índice, não havendo divulgação a seu respeito caso não logre compor o índice. Apesar de eventuais limitações em processos avaliativos tão complexos, é bastante positiva a existência de índices como o ISE que pode ser um impulsionador da preocupação socioambiental das empresas. A evidência encontrada de alta persistência das empresas no índice como de divulgação de questionários já é um efeito positivo decorrente de sua implantação.

Ao encontrar evidência de que há uma persistência de empresas que figuram no ISE, e que as empresas apresentam tendência a tornar público o conteúdo de seus questionários de candidatura ao ISE, o trabalho contribui para a literatura de RSC sob os marcos teóricos das Teorias da Legitimação, Divulgação Voluntária, e Stakeholder. Para a academia, os resultados, além de dar suporte a estes enfoques teóricos, também se somam àqueles que analisam índices 
de mercado como instrumentos externos de avaliação de RSC que têm observado crescente importância. Sob a óptica da sociedade, o trabalho apresenta a contribuição de expor o processo avaliativo de empresas que compõem o ISE ao mesmo tempo em que mostra haver fortes sinais de que as empresas estão competindo fortemente para serem listadas no índice, o que exige uma melhoria efetiva na ação socioambiental das mesmas, podendo ter reflexo positivo para o conjunto da sociedade.

Como perspectiva de trabalhos futuros, mencionamos o desenvolvimento de pesquisa qualitativa e quantitativa sobre o conteúdo dos questionários divulgados explorando-se o grau de preocupação socioambiental da empresa por dimensão específica. Outra possibilidade de trabalho que se vislumbra é a avaliação conjunta de indicadores socioambientais com o objetivo de verificar se empresas são capazes de obter bom desempenho em distintos índices de avaliação socioambiental ou se há distorção entre eles.

\section{NOTA}

[1] Exemplos de organizações que atuam nesta área são MSCI ESG Research (https://www.msci. $\mathrm{com} /$ research/esg-research) e Calvert Investments (http://www.calvert.com). Podem também ser aí elencadas as Bolsas de Valores que começam a atuar neste sentido.

\section{REFERÊNCIAS}

ADAMS, C. A. A commentary on: corporate social responsibility reporting and reputation risk management. Accounting, Auditing \& Accountability Journal, v. 21, n. 3, p. 365-370, 2008.

AGARWAL, V.; NAIK, N. Y. Multi-Period Performance Persistence Analysis of Hedge Funds. The Journal of Financial and Quantitative Analysis, v. 35, n. 3, p. 327-342, 2000.

ALI, W.; ALSAYEGH, M. F.; AHMAD, Z.; MAHMOOD, Z.; IQBAL, J. The Relationship between Social Visibility and CSR Disclosure. Sustainability, v. 10, n. 3, p. 866-897, 2018.

ALI, W.; FRYNAS, J. G.; MAHMOOD, Z. Determinants of Corporate Social Responsibility (CSR) Disclosure in Developed and Developing Countries: A Literature Review. Corporate Social Responsibility and Environmental Management, v. 24, n. 4, p. 273-294, 2017.

ALON, I.; LATTEMANN, C.; FETSCHERIN, M.; LI, S.; SCHNEIDER, A.-M. Usage of public corporate communications of social responsibility in Brazil, Russia, India and China (BRIC). International Journal of Emerging Markets, v. 5, n. 1, p. 6-22, 2010.

BARAIBAR-DIEZ, E.; SOTORRÍO, L. L. O efeito mediador da transparência na relação entre responsabilidade social corporativa e reputação corporativa. Revista Brasileira de Gestao de Negocios, v. 20, n. 1, p. 5-21, 2018.

BARTH, M. E.; CAHAN, S. F.; CHEN, L.; VENTER, E. R. The economic consequences associated with integrated report quality: Capital market and real effects. Accounting, Organizations and Society, v. 62, p. 43-64, 2017/10/01/ 2017.

BAUGHN, C. C.; BODIE, N. L. D.; MCINTOSH, J. C. Corporate Social and Environmental Responsibility in Asian Countries and Other Geographical Regions. Corporate Social Responsibility and 
Environmental Management, v. 14, n. 4, p. 189-205, 2007.

BEBBINGTON, J.; LARRINAGA-GONZÁLEZ, C.; MONEVA-ABADÍA, J. M. Legitimating reputation/the reputation of legitimacy theory. Accounting, Auditing \& Accountability Journal, v. 21, n. 3, p. 371-374, 2008.

BM\&FBOVESPA. Índice de Sustentabilidade Empresarial - ISE. Bolsa de Valores de São Paulo. v. 2012. n. 10 nov2012.

. Metodologia do Índice de Sustentabilidade Empresarial (ISE). São Paulo: Bolsa de Valores de São Paulo, 2015.

Índice de Sustentabilidade Empresarial - ISE 10 Anos. v. 2016. n. Outubro. São Paulo: Bolsa de Valores de São Paulo e Fundação Getulio Vargas, 2016.

BOUTEN, L.; EVERAERT, P.; VAN LIEDEKERKE, L.; DE MOOR, L.; CHRISTIAENS, J. Corporate social responsibility reporting: A comprehensive picture? Accounting Forum, v. 35, n. 3, p. 187-204, 2011.

BRAGA, C.; SILVA, P. P.; SANTOS, A. Level of Disclosure of Environmental Information in the Electricity Sector: An Empirical Study of Brazil and the Iberian Peninsula. Global Journal of Management and Business Research, v. 15, n. 9, p. 39-53, 2015.

BRAMMER, S.; JACKSON, G.; MATTEN, D. Corporate Social Responsibility and institutional theory: new perspectives on private governance. Socio-Economic Review, v. 10, n. 1, p. 3-28, 2012.

BROWN, J. A.; FORSTER, W. R. CSR and Stakeholder Theory: A Tale of Adam Smith. Journal of Business Ethics, v. 112, n. 2, p. 301-312, 2013.

BROWN, S. J.; GOETZMANN, W. N. Performance Persistence. The Journal of Finance, v. 50, n. 2, p. 679-698, 1995.

CALDELLI, A.; PARMIGIANI, M. L. Management Information System- A tool for Corporate Sustainability. Journal of Business Ethics, v. 55, 2004.

CARROLL, A. B. Corporate Social Responsibility: Evolution of a Definitional Construct. Business \& Society, v. 38, n. 3, p. 268-295, 1999.

CIRIACO FERNÁNDEZ, A.; SANTAMARÍA AQUILUÉ, R. Persistencia de resultados en los fondos de inversión españoles. Investigaciones Económicas, v. 29, n. 3, p. 525-573, 2005.

CLARKSON, P. M.; FANG, X.; LI, Y.; RICHARDSON, G. The relevance of environmental disclosures: Are such disclosures incrementally informative? Journal of Accounting and Public Policy, v. 32, n. 5, p. 410-431, 2013/09/01/2013.

COCHRAN, P. L. The evolution of corporate social responsibility. Business Horizons, v. 50, n. 6, p. 449-454, 2007.

COLARES, A. C. V.; BRESSAN, V. G. F.; LAMOUNIER, W. M.; BORGES, D. L. O BALANÇO SOCIAL COMO INDICATIVO SOCIOAMBIENTAL DAS EMPRESAS DO ÍNDICE DE SUSTENTABILIDADE EMPRESARIAL DA BM\&FBOVESPA. Revista de Contabilidade do Mestrado em Ciências Contábeis da UERJ, v. 17, n. Ed. Especial, p. 83-100, 2012. 
CRISÓSTOMO, V. L.; FREIRE, F. S. The Influence of Ownership Concentration on Firm Resource Allocations to Employee Relations, External Social Actions, and Environmental. Review of Business Management (Revista Brasileira de Gestão de Negócios), v. 17, n. 55, p. 987-1006, 2015.

CRISÓSTOMO, V. L.; FREIRE, F. S.; VASCONCELLOS, F. C. Corporate social responsibility, firm value and financial performance in Brazil. Social Responsibility Journal, v. 7, n. 2, p. 295-309, 2011.

CRISÓSTOMO, V. L.; SOUZA, J. L.; PARENTE, P. H. N. Possível efeito regulatório na responsabilidade socioambiental da empresa brasileira em função da Lei $n^{\circ} 10.165 / 2000$. Revista de Gestão Social e Ambiental, v. 6, n. 3, p. 157-170, 2012.

DAHLSRUD, A. How corporate social responsibility is defined: an analysis of 37 definitions. Corporate Social Responsibility and Environmental Management, v. 15, n. 1, p. 1-13, 2008.

DANTAS, P. A.; NUNES, R. V.; ASSIS, C. W. C.; ADRIANO, N. A.; FONSECA, R. D. C. Nível de evidenciação dos indicadores ambientais e sociais sob a perspectiva da análise hierárquica de processos (ahp) - um estudo exploratório nas empresas com melhor desempenho no índice de sustentabilidade empresarial (ise) em 2013. GEPROS. Gestão da Produção, Operações e Sistemas, v. 11, n. 1, p. 1-28, 2016.

DE LOS RÍOS BERJILLOS, A.; RUIZ LOZANO, M.; TIRADO VALENCIA, P.; CARBONERO RUZ, M. Una aproximación a la relación entre información sobre la responsabilidad social orientada al cliente y la reputación corporativa de las entidades financieras españolas. Cuadernos de Economía y Dirección de la Empresa, v. 15, n. 3, p. 130-140, 2012.

DEEGAN, C. The legitimising effect of social and environmental disclosures - a theoretical foundation. Accounting, Auditing \& Accountability Journal, v. 15, n. 3, p. 282-311, 2002.

DIMAGGIO, P. J.; POWELL, W. W. The Iron Cage Revisited: Institutional Isomorphism and Collective Rationality in Organizational Fields. American Sociological Review, v. 48, n. 2, p. 147-160, 1983.

DOBERS, P.; HALME, M. Corporate social responsibility and developing countries. Corporate Social Responsibility and Environmental Management, v. 16, n. 5, p. 237-249, 2009.

DOH, J. P.; HOWTON, S. D.; HOWTON, S. W.; SIEGEL, D. S. Does the Market Respond to Endorsement of Social Responsibility? The Role of Institutions, Information, and Legitimacy. Journal of Management, v. 36, n. 6, p. 1461-1485, 2010.

EUGÉNIO, T. AVANÇOS NA DIVULGAÇÃO DE INFORMAÇÃO SOCIAL E AMBIENTAL PELAS EMPRESAS E A TEORIA DA LEGITIMIDADE. Revista Universo Contábil, v. 6, n. 1, p. 102-118, 2010.

FARIA, A.; SAUERBRONN, F. F. A responsabilidade social é uma questão de estratégia? Uma abordagem crítica. Revista de Administração Pública, v. 42, n. 1, p. 7-33, 2008.

FREEMAN, R. E.; PHILLIPS, R. A. Stakeholder Theory: A Libertarian Defense. Business Ethics Quarterly, v. 12, n. 3, p. 331-349, 2002.

FREEMAN, R. E.; RUSCONI, G.; SIGNORI, S.; STRUDLER, A. Stakeholder Theory(ies): Ethical Ideas and Managerial Action. Journal of Business Ethics, v. 109, n. 1, p. 1-2, 2012.

FREEMAN, R. E.; WICKS, A. C.; PARMAR, B. Stakeholder Theory and "The Corporate Objective Revisited". Organization Science, v. 15, n. 3, p. 364-369, 2004. 
GALAN, J. I. Corporate Social Responsibility and Strategic Management (Review Essay). Journal of Management Studies, v. 43, n. 7, p. 1629-1641, 2006.

GAMERSCHLAG, R.; MÖLLER, K.; VERBEETEN, F. Determinants of voluntary CSR disclosure: empirical evidence from Germany. Review of Managerial Science, v. 5, n. 2, p. 233-262, 2011.

GJøLBERG, M. Measuring the immeasurable?: Constructing an index of CSR practices and CSR performance in 20 countries. Scandinavian Journal of Management, v. 25, n. 1, p. 10-22, 2009.

HARRISON, J. S.; BOSSE, D. A.; PHILLIPS, R. A. Managing for stakeholders, stakeholder utility functions, and competitive advantage. Strategic Management Journal, v. 31, n. 1, p. 58-74, 2010.

HEATH, R. L.; LEE, J. Chemical Manufacturing and Refining Industry Legitimacy: Reflective Management, Trust, Precrisis Communication to Achieve Community Efficacy. Risk Analysis, v. 36, n. 6, p. 1108-1124, 2016.

HUIJ, J.; VERBEEK, M. Cross-sectional learning and short-run persistence in mutual fund performance. Journal of Banking \& Finance, v. 31, n. 3, p. 973-997, 2007.

JENSEN, M. C.; MECKLING, W. H. Theory of the Firm: Managerial Behavior, Agency Cost and Ownership Structure. Journal of Financial Economics, v. 3, n. 4, p. 305-360, 1976.

KAHN, R. N.; RUDD, A. Does Historical Performance Predict Future Performance? Financial Analysts Journal, v. 51, n. 6, p. 43-52, 1995.

LAMARCHE, T.; RUBINSTEIN, M. Dynamics of corporate social responsibility: towards a new 'conception of control'? Journal of Institutional Economics, v. 8, n. 2, p. 161-186, 2012.

MAIGNAN, I. Consumers' Perceptions of Corporate Social Responsibilities: A Cross-Cultural Comparison. Journal of Business Ethics, v. 30, n. 1, p. 57-72, 2001.

MALKIEL, B. G. Returns from Investing in Equity Mutual Funds 1971 to 1991 . The Journal of Finance, v. 50, n. 2, p. 549-572, 1995.

MARGOLIS, J. D.; WALSH, J. P. People and profits?: The search for a link between a company's social and financial performance. Mahwah, NJ: Lawrence Erlbaum Associates, Inc, 2001.

MARTINS, G. A.; THEÓPHILO, C. R. Metodologia da investigação científica para ciências sociais aplicadas. 2. ed. São Paulo: Atlas, 2009.

MCVEA, J. F.; FREEMAN, R. E. A Names-and-Faces Approach to Stakeholder Management - How Focusing on Stakeholders as Individuals Can Bring Ethics and Entrepreneurial Strategy Together. Journal of Management Inquiry, v. 14, n. 1, p. 57-69, 2005.

MICHAELS, A.; GRÜNING, M. The impact of corporate identity on corporate social responsibility disclosure. International Journal of Corporate Social Responsibility, v. 3, n. 1, p. 3, February 21 2018.

MILANI, B.; RIGHI, M. B.; CEVETTA, S.; DIAS, V. V. D. Práticas de sustentabilidade, governança corporativa e responsabilidade social afetam o risco e o retorno dos investimentos? Revista de Administração da UFSM, Santa Maria, v. 5, n. Edição Especial, p. 667-682, 2012.

MYNHARDT, H.; MAKARENKO, I.; PLASTUN, A. Market efficiency of traditional stock market indices 
and social responsible indices: the role of sustainability reporting. Investment Management and Financial Innovations, v. 14, n. 2, p. 94-106, 2017.

NASCIMENTO, A. R.; SANTOS, A.; SALOTTI, B.; MÚRCIA, F. D.-R. Disclosure Social e Ambiental: Análise das Pesquisas Científicas Veiculadas em Periódicos de Língua Inglesa. Revista Contabilidade Vista \& Revista, v. 20, n. 1, p. 15-40, 2009.

ORIDE, K. S.; MYSZCZUK, A. P. Gestão empresarial e desenvolvimento sustentável: Análise a partir da carteira ISE da Bolsa de Valores de São Paulo (2011-2015). Revista Brasileira de Planejamento e Desenvolvimento, v. 6, n. 1, 2017.

ORLITZKY, M.; SCHMIDT, F. L.; RYNES, S. L. Corporate Social and Financial Performance: A MetaAnalysis. Organization Studies, v. 24, n. 3, p. 403-441, 2003.

ORSATO, R. J.; GARCIA, A.; MENDES-DA-SILVA, W.; SIMONETTI, R.; MONZONI, M. Sustainability indexes: why join in? A study of the 'Corporate Sustainability Index (ISE)' in Brazil. Journal of Cleaner Production, v. 96, p. 161-170, 2015.

PATTEN, D. M. Exposure, legitimacy, and social disclosure. Journal of Accounting and Public Policy, v. 10, n. 4, p. 297-308, 1991/12/01/ 1991.

PLETSCH, C. S.; BRIGHENTI, J.; SILVA, A.; ROSA, F. S. Perfil da Evidenciação Ambiental das Empresas Listadas no Índice de Sustentabilidade Empresarial. Revista Contabilidade Vista \& Revista, v. 25, n. 3, p. 57-77, 2014.

PLUMLEE, M.; BROWN, D.; HAYES, R. M.; MARSHALL, R. S. Voluntary environmental disclosure quality and firm value: Further evidence. Journal of Accounting and Public Policy, v. 34, n. 4, p. 336-361, 2015/07/01/2015.

REAST, J.; MAON, F.; LINDGREEN, A.; VANHAMME, J. Legitimacy-Seeking Organizational Strategies in Controversial Industries: A Case Study Analysis and a Bidimensional Model. Journal of Business Ethics, v. 118, p. 139-153, 2013.

RICHARDISON, R. J. Pesquisa social: métodos e técnicas. 3. ed. São Paulo: Atlas, 1999.

ROBERTSON, D. C. Corporate Social Responsibility and Different Stages of Economic Development: Singapore, Turkey, and Ethiopia. Journal of Business Ethics, v. 88, p. 617-633, 2009.

RUFINO, M. A.; MACHADO, M. R. Fatores Determinantes da Divulgação de Informações Voluntária Social: Evidências Empíricas no Brasil. Revista de Educação e Pesquisa em Contabilidade (REPeC), v. 9, n. 4, p. 380-396, 2015.

SCHWARTZ, M. S.; CARROLL, A. B. Integrating and unifying competing and complementary frameworks: The search for a common core in the business and society field. Business and Society Review, v. 47, n. 2, p. 148-186, 2008.

SEE, G. K. H. Harmonious Society and Chinese CSR: Is There Really a Link? Journal of Business Ethics, v. 89, n. 1, p. 1-22, 2009.

SHRIVASTAVA, P. Ecocentric management for a risk strategy. Academy of Management Review, v. 20, n. 1, p. 118-137, 1995. 
SKILLIUS, A.; WENNBERG, U. Continuity, credibility and comparability: key challenges for corporate environmental performance measurement and communication. Lund University. 1998

STATMAN, M. Socially Responsible Indexes. Journal of Portfolio Management, v. 3, p. 100-109, 2006.

SUTANTOPUTRA, A. W. Social disclosure rating system for assessing firms' CSR reports. Corporate Communications: An International Journal, v. 14, n. 1, p. 34-48, 2009.

TILLING, M. V.; TILT, C. A. The edge of legitimacy: voluntary social and environmental reporting in Rothmans' 1956-1999 annual reports. Accounting, Auditing \& Accountability Journal, v. 23, p. 55-81, 2010.

TSCHOPP, D.; HUEFNER, R. J. Comparing the Evolution of CSR Reporting to that of Financial Reporting. Journal of Business Ethics, v. 127, n. 3, p. 565-577, 2015.

TULLBERG, J. Stakeholder theory: Some revisionist suggestions. The Journal of Socio-Economics, v. 42, p. 127-135, 2013

VAN MARREWIJK, M.; WERRE, M. Multiple Levels of Corporate Sustainability. Journal of Business Ethics, v. 44, n. 2-3, p. 107-119, 2003.

VERRECCHIA, R. E. Essays on disclosure. Journal of Accounting and Economics, v. 32, p. 97-180, 2001.

VIANA JUNIOR, D. B. C.; CRISÓSTOMO, V. L. Nível de Disclosure Socioambiental: Uma Análise Comparativa entre Empresas Brasileiras de Acordo com o Potencial de Agressão ao Meio Ambiente. Revista de Administração da UFSM, v. 10, n. Ed. Especial, p. 79-99, 2017.

WILLIAMS, C. A.; AGUILERA, R. V. Corporate Social Responsibility in Comparative Perspective. In: CRANE, A. et al (Ed.). Oxford Handbook of Corporate Social Responsibility. Oxford: Oxford University Press, 2008. Cap.3. p. 167-214.

WOOD, D. J. Corporate Social Performance Revisited. The Academy of Management Review, v. 16, n. 4, p. 691-718, 1991. 